\title{
RSP Revisitada A revolução da informática chega à administração
}

Paulo Jobim Filho

Texto publicado na RSP, vol. 113, n 1, março de 1985.

\begin{abstract}
As inovações tecnológicas e a crescente demanda dos cidadãos por informações acerca da atuação do Estado vêm convergindo na consolidação de instituições garantidoras da transparência governamental. Esse diagnóstico é um desdobramento recente da introdução da informática e de outras tecnologias de informação no funcionamento da administração pública no Brasil. Os desafios de implantação e possibilidades iniciais dessas tecnologias são abordados pelo economista Paulo Jobim Filho, no texto $A$ revolução da informática chega à administração, de 1985 . Nesse sentido, a informática e suas constantes transformações vêm desempenhando um importante papel na mudança de postura dos agentes públicos quanto ao fornecimento de informações ao público interessado. Antes restrita ao âmbito técnico-operacional, a informática, hoje, faz parte do cotidiano da administração pública brasileira e das interações entre Estado e sociedade civil. Apesar dos nítidos avanços, o tema das tecnologias de informação representa um desafio constante para a administração pública, especialmente no tocante à formação de servidores capacitados para atender às exigências de uma sociedade democrática cada vez mais informatizada, o que torna muito atual a "estratégia apoiada na educação", desenvolvida pelo artigo revisitado.
\end{abstract}

\section{A administração pública em uma sociedade a caminho da informatização}

Tudo indica que a informática já está provocando mudanças profundas na nossa forma de pensar e agir, que acabarão refletindo na organização política, econômica e cultural da sociedade brasileira. 
Muito mais que as revoluções tecnológicas do passado, a "revolução informática" está destinada a afetar a sociedade de forma global, criando novas relações entre os agentes econômicos, definindo novas fórmulas de convivência política, mudando concepções tradicionais de educação, interferindo na cultura e, até mesmo, ameaçando a soberania das nações (Toffler, 1980; Naisbtt, 1983). A informática constituir-se-á no fator comum de facilitação e indução de todo o processo de inovação tecnológico nas outras áreas do conhecimento.

A informática da década passada era elitista. Utilizada pelas grandes organizações, era muito cara e esotérica para a maioria das pessoas. O desenvolvimento surpreendente da eletrônica e das telecomunicações tem permitido sua gradativa massificação. Há dez anos seria difícil imaginar que a informática se tornasse tão popular, despertando o interesse do cidadão comum, do profissional, do jovem em idade escolar, de segmentos tão expressivos e diferenciados da sociedade.

Os computadores herméticos, reservados aos profissionais da área, começam a ser operados por leigos e até por crianças. Estão deixando também, gradativamente, de ser isolados, isto é, estão passando a se comunicar por meio de redes cada vez mais interconexas.

Tudo isso representa, afinal, a caminhada para a sociedade da informação e nada melhor para caracterizá-la que seus efeitos visíveis, isto é, a enorme variedade de aplicações do computador no cotidiano do cidadão, no ambiente profissional, na educação, no lar.

A passagem da sociedade industrial para a sociedade da informação transfere a ênfase da automatização do trabalho muscular para o processamento da infor- mação mediante recursos técnicos, significando a abstração do material e a representação do mundo físico por figuras informacionais.

Visto que a administração pública lida essencialmente com o processamento de informações, ela será particularmente afetada por todo esse processo de mudança desencadeado pela informática, o que sugere sua preparação para absorver, de forma produtiva e racional, os impactos dessas transformações (REINERMANN, 1985).

No momento em que se inicia em nosso país um novo esforço de reforma da administração pública e se aproxima a convocação da Assembleia Nacional Constituinte, é de todo conveniente discutir a oportunidade de utilização da informática com instrumento viabilizador de transformações no panorama da administração pública brasileira e, por que não dizer, da própria sociedade. Esse trabalho foi desenvolvido com o intuito de iniciar esses debates, oferecendo sugestões que poderão servir como ponto de partida para uma discussão mais aprofundada em torno do tema.

\section{O desenvolvimento da infor- mática e os impactos sobre os usuários}

A revolução informática, caracterizada por um conjunto vertiginoso de inovações tecnológicas que conduzem à sociedade da informação, tem cerca de trinta anos e o que mais distingue esse desenvolvimento tem sido a velocidade com que evoluem os diversos aspectos dessa tecnologia.

Os primeiros computadores eram grandes, lentos (para os padrões de hoje), caros e apresentavam defeitos com frequência. Entre 1950 e 1980, as dimensões externas foram reduzidas na ordem 
de 1.000 vezes; a velocidade de operação, multiplicada em mais de 60.000; o tempo médio entre defeitos, então medido em horas, é agora medido em anos; o custo caiu verticalmente: um custo computacional de 1 dólar hoje teria custado, em 1950, 28.000 dólares; e um armazenamento de dados de alta velocidade que hoje custa 1 dólar, teria custado 2.600 dólares em 1950 (HaLl, 1982).

$\mathrm{O}$ fator preponderante para o rápido desenvolvimento da informática foi o progresso verificado nas áreas da eletrônica (miniaturização de circuitos) e de telecomunicações.

A miniaturização da eletrônica começou com o transistor e seu desenvolvimento posterior foi grandemente influenciado pelo programa espacial norte- americano, tendo sido o circuito integrado a inovação fundamental. Esses circuitos permitiram que se pudessem construir computadores cada vez mais potentes e menores. Atualmente, computadores inteiros podem ser colocados em uma pastilha de material semicondutor (silício), de aproximadamente $1 \mathrm{~cm}^{2}$ de área.

Para os usuários da informática, o desenvolvimento tecnológico nesse campo pode ser dividido, na prática, em dois momentos: antes e depois do aparecimento do mini e dos microcomputadores nos anos 70, inovações que, de fato, começaram a abrir novas perspectivas de utilização maciça dos computadores pelo conjunto da sociedade.

O problema do excesso de centralismo dos recursos de processamento eletrônico de dados originou-se, sem dúvida alguma, no alto custo (cerca de 1 milhão de dólares) dos computadores nos anos 60, na ideia, então generalizada, de que se obteria economia de escala nos grandes computadores (lei de Grosch) e no mito da complexidade do processamento eletrônico de dados.

O conjunto desses fatores acabou sugerindo às empresas que centralizassem seus recursos de processamento em um único órgão, reunindo os meios e as atividades relacionadas ao desenvolvimento e à operação dos sistemas de interesse de toda a organização. Surgiam, desta forma, os CPDS (Centros de Processamento de Dados).

A verdade é que a "tecnologia de processamento eletrônico de dados impôs aos usuários finais, como preço de seus benefícios, não só um órgão centralizado para criar e processar os sistemas, mas também o ajustamento das estruturas, métodos e técnicas de trabalho dos usuários às ferramentas computacionais disponíveis a época" (Burgos, 1985).

\section{O setor público vem realizando expressivos} investimentos no processamento de dados desde 1970, mas sua utilização continua restrita ao ambiente técnico-operacional de apoio a atividades-meio. $O$ computador, enfim, tem sido usado com timidez $\mathrm{e}$ ineficiência.

Em oposição a essa concepção centralizadora, e portando "fechada", de interação entre o prestador de serviços e o usuário, surge nesta década uma nova concepção "aberta" de automatização, em que os recursos computacionais são colocados à disposição dos usuários no seu próprio local de trabalho, para que estes 
desenvolvam e operem as aplicações de seu interesse. Essa filosofia de descentralização, como veremos ao longo deste trabalho, sugere inúmeras oportunidades de renovação organizacional que podem ser aproveitadas pela Reforma.

\section{O panorama atual da infor- mática na administração pública}

Desde o início da década de 70, o setor público vem realizando investimentos expressivos no processamento de dados apoiados em computador.

Como resultado desses investimentos, a maioria dos órgãos públicos (administração direta e indireta) dispõe de modernos centros de processamento de dados, equipados com grandes processadores de origem estrangeira, onde são projetados e operados os sistemas de interesse dessas organizações.

A despeito dos investimentos realizados na constituição desses centros de processamento de dados, percebem-se problemas do seguinte tipo:

- Destinado a uma utilização quase sempre restrita ao ambiente técnico-operacional de apoio a atividades meio, o processamento de dados tem sido usado com timidez na melhoria dos resultados das agências governamentais, isto é, no aumento da capacidade de executar programas, no acompanhamento, avaliação e atuação frente às modificações ambientais e na formulação e desenvolvimento de políticas governamentais.

- Os usuários, em grande número de organizações públicas, se queixam de que o centro de processamento de dados não atende adequadamente às suas necessidades, não lhes fornece as informações indispensáveis para o seu trabalho e costuma adotar postura inflexível sempre que se solicita alguma alteração, buscando adequar os sistemas às suas necessidades reais, atuais e potenciais.

Fora esse clima de tensão entre usuários e prestadores de serviços, a verdade é que o processamento eletrônico de dados não tem sido, até o momento, na maioria das organizações governamentais, um instrumento de efetiva renovação dos métodos de trabalho e da própria melhoria do desempenho gerencial. Por mais que se imaginasse que a informática provocaria mudanças drásticas na forma de atuação dos órgãos públicos, isso de fato não aconteceu no panorama da administração pública até agora, pelo menos sob a égide dos grandes centros de processamentos de dados.

\section{A informática distribuída como uma oportunidade para pro- vocar mudanças}

A rigidez e a baixa produtividade inerentes ao modelo centralizado de prestação de serviços na área do processamento eletrônico de dados eram problemas praticamente insolúveis no quadro da tecnologia disponível nas décadas de 60 e 70 . Os avanços posteriores em hardware e software, coroados pelo aparecimento dos microcomputadores, acabaram sugerindo uma solução natural para os problemas anteriormente apontados, ou seja: colocar à disposição do usuário recursos computacionais para que ele próprio desenvolva as aplicações de seu interesse, capacitando-o, dessa forma, a resolver seus problemas mais imediatos sem a interferência dos centros de processamento de dados.

Essa abordagem descentralizada de utilização de recursos abre novas e fundadas expectativas nas organizações, considerando-se, entre outras, as seguintes razões: 
O sucesso da reforma na administração pública passa necessariamente pela melhoria do desempenho na execução de programas (eficácia gerencial) e na busca de novas formas de administrar os negócios públicos, baseada na maior capacidade organizacional de atender aos anseios da comunidade. Nesse sentido, a busca da racionalidade interna e $o$ propósito social da organização são duas dimensões que devem ser tratadas conjunta e harmonicamente, não só na formulação de objetivos, mas também na estrututuração da própría organização.

- Tarefas de rotina poderão ser transferidas para a máquina, induzindo-se a gerência a dedicar-se a atividades não mecânicas, mais criativas e mais analíticas.

- A divisão do trabalho pode ser reduzida, obtendo-se vantagens decorrentes da maior motivação do funcionário pelo seu trabalho (job enrichment), menores despesas de comunicação e maior integração das diversas atividades organizacionais.

- A descentralização, por meio da delegação, pode ser alcançada com mais facilidade, uma vez que os dirigentes podem dispor de um maior número de informações sobre a qualidade na execução das tarefas delegadas.

- O relacionamento entre os centros de processamento de dados e os usuários deve melhorar, na medida em que estes últimos incorporem uma cultura técnica na área, através de uma maior familiarização com o computador.

- A ideia de microaplicações desenvolvidas diretamente pelo usuário, de modo que as transformações se dão de forma incremental e progressiva, deve produzir resultados mais favoráveis no que tange ao seu potencial de provocar mudanças nas organizações efetivas.

- No que se refere às questões de resistência à mudança e às ações de contra implementação, as perspectivas são igualmente otimistas. Isso porque as modificações propostas no modelo descentralizado não invadem o "território" do usuário, mas, pelo contrário, são por ele geridas e controladas, o que, na prática, significa uma menor resistência à introdução da tecnologia do processamento eletrônico de dados nas organizações.

O funcionário do guichê, por outro lado, pode passar a dispor de mais poder decisório, mais autoridade funcional, em vez de ser um mero preenchedor de papéis ou distribuidor de informações incompletas e às vezes conflitantes.

Não há dúvida, portanto, de que o processamento distribuído, descentralizado, possui um elevado potencial para provocar mudanças organizacionais, melhorar o apoio à tomada de decisões do administrador público e aumentar a flexibilidade, presteza e correção no atendimento ao cidadão que se dirige aos órgãos públicos. A grande questão que deve ser colocada passa a ser, então, a seguinte: como transformar esse potencial em resultados concretos? 


\section{Uma estratégia apoiada na educação}

O sucesso do esforço de reforma da administração pública brasileira passa necessariamente pela melhoria do desempenho na execução de programas (eficácia gerencial) e na busca de uma nova forma de administrar os negócios públicos, baseada na maior capacidade organizacional de atender aos anseios da comunidade. Nesse sentido, a busca da racionalidade interna e o propósito social da organização são duas dimensões que devem ser tratadas conjunta e harmonicamente, não só na formulação de objetivos, mas também na estruturação da própria organização (Mотта, 1985).

A tecnologia da informática distribuída pode ser, como vimos ao longo deste trabalho, um importante instrumento de aperfeiçoamento gerencial, mormente no que se refere à mudança de um estilo de trabalho centrado no ritual processualístico para outro estilo mais voltado para resultados no atendimento a objetivos, com ênfase na própria dimensão social da organização pública.

Mas o aperfeiçoamento gerencial via informática pressupõe o desencadeamento de uma ampla ação de natureza educacional no âmbito do serviço público, com as seguintes características:

- Oferecimento pelos órgãos de treinamento do serviço público de uma linha de programas educacionais em microinformática para gerentes, dentro de uma abordagem prática de solução de problemas, a partir de pacotes genéricos de software de fácil assimilação e utilização por não especialistas (planilhas eletrônicas, plotadores de gráficos, editores de textos e gerenciadores de base de dados), que seriam utilizados na solução de problemas decisórios característicos do ambiente de trabalho do usuário;

- Elaboração de um material instrucional completo para treinamento de usuários à distância ou por meio de autoinstrução (módulo e vídeos, por exemplo), de forma a permitir a mais ampla disseminação de conhecimentos nessa área e a efetiva democratização das oportunidades educacionais na aquisição desses conhecimentos;

- Desenvolvimento de estudos e pesquisas ligados à microinformática na administração pública, visando a disseminar conhecimentos e recomendar procedimentos nessa área, além de indicar prioridades para investimentos governamentais;

- Promoção de eventos que possibilitem o intercâmbio de experiências, o desenvolvimento de ações conjuntas e impulsionem mudanças nesse campo (encontros, feiras de experiências, concurso de monografias, oficinas de microinformática para os funcionários públicos e para a comunidade, e assim por diante).

\section{Conclusões}

Valendo-se da própria evolução tecnológica que se tem verificado nas áreas de microeletrônica e telecomunicações, a Reforma Administrativa pode ajudar a mudar o panorama atual, fazendo com que a informática no setor público seja, de fato, um instrumento viabilizador de transformações profundas que privilegiem a sociedade brasileira, oferecendo-lhe serviços de boa qualidade, e que possibilitem, afinal, o aumento da capacidade de gestão dos negócios públicos nos vários níveis da administração. 


\section{Referências}

Burgos, A. Mujica. Micro nas Empresas: Tábua de Salvação dos Usuários, Dados e Idéias, maio de 1985, págs. 47 a 56.

Hall, K. A. Computer - Based Education, in H.E. Mitzel, ed. Encyclopedia of Educational - Reseach, Vol. I; NY, Free/Macmillan, 1982.

Мотта, P. Roberto. A Realidade da Administração Pública Brasileira, texto apresentado para discussão na Comissão Geral da Reforma Administrativa, Brasilia, 1985.

Naisbitt, J. Megatendências. São Paulo, Abril, 1983.

Reinermann, Heinrich. A Moderna Teconologia da Informação: Uma convocação aos gerentes para iniciar reformas na Administração Pública, DataNews, no2 272, de 21 de maio de 1985, págs. 33 e 34.

Toffler, A. A Terceira Onda, Rio de Janeiro, Record, 1980. 